\title{
Rancangan Bangun Sistem Pakar Menentukan Bakat Anak Menggunakan Metode Forward Chaining
}

\author{
Hadi Jayusman ${ }^{1)}$, Sandi Najib Iskandar ${ }^{2)}$, Korisaputri ${ }^{3)}$ \\ 1) Program Studi Teknologi Informasi, Universitas Harapan Bangsa, Purwokerto \\ hadijayusmaneuhb.ac.id \\ ${ }^{2) 3)}$ Program Studi Informatika, Universitas Harapan Bangsa, Purwokerto \\ 2) sandinajib2001@gmai.com \\ 3) chorisaputriegmail.com
}

\begin{abstract}
Every child is born with the talent and personality of each and unique. As parents naturally want to provide a good education for their children. Sometimes a good education is not necessarily appropriate for the child. Because every child has different talent . Provision of learning patterns that are inconsistent with the child's personality. Errors in providing education or learning patterns that do not conform with the talents of children, the child eventually burdened with. The expert system is used to determine the appropriate talent in a child's personality use Forward Chaining models.
\end{abstract}

Keywords- Expert System, Expert System, Talent , Forward Chaining

Instisari- Setiap anak terlahir dengan bakat dan kepribadiannya masing-masing dan unik. Sebagai orang tua tentu ingin memberikan pendidikan yang baik untuk anak mereka. Pendidikan yang baik terkadang belum tentu yang tepat untuk anak tersebut. Karena setiap anak punya bakat yang berbeda. Pemberian pola belajar yang tidak sesuai dengan kepribadian anak. Kesalahan dalam memberikan pendidikan atau pola belajar yang tidak sesuai dengan bakat anak, pada akhirnya anak terbebani dengan pendidikan yang mereka jalani. Sistem pakar yang digunakan untuk menentukan bakat pada anak sesuai kepribadian mengggunakan model Forward Chaining. Hasil dari penelitian ini adalah aplikasi sistem pakar bakat anak berdasarkan kepribadian anak.

Kata kunci-Sistem Pakar, Bakat, Forward Chaining

\section{PENDAHULUAN}

Sistem pakar merupakan suatu sistem yang menggabungkan pengetahuan dan penelusuran data untuk memecahkan masalah yang secara normal memerlukan keahlian seorang pakar atau ahli. Pemanfaatan sistem pakar biasanya berupa konsultasi, melakukan analisa dan diagnosis, membantu dalam pengambilan keputusan, memberi solusi dan lain-lain. Salah satu implementasi sistem pakar dalam bidang kesehatan lebih tepatnya di bidang psikologi adalah untuk menentukan bakat anak berdasarkan kepribadian. Dalam kasus ini domain knowledge nya adalah kepribadian yang terdiri dari knowledge tentang berbagai sifat dan bakat.

Setiap anak terlahir dengan bakat dan kepribadiannya masing-masing dan unik. Sebagai orang tua tentu ingin memberikan pendidikan yang baik untuk anak mereka. Pendidikan yang baik terkadang belum tentu yang tepat untuk anak tersebut. Karena setiap anak punya bakat yang berbeda. Pemberian pola belajar yang tidak sesuai dengan kepribadian anak. Kesalahan dalam memberikan pendidikan atau pola belajar yang tidak sesuai dengan bakat anak, pada akhirnya anak terbebani dengan pendidikan yang mereka jalani. Oleh sebab itulah sistem pakar ini dibuat untuk membantu orang tua agar dapat mengetahui bakat anak mereka yang sesuai dengan kepribadian anak, sehingga orang tua dapat memberikan pendidikan dan pola belajar yang tepat bagi anak mereka. Serta anak dapat memaksimalkan potensi bakat yang mereka punya dan menikmati masa kecil mereka tanpa adanya beban dari orang tua, karena kesalahan menentukan pendidikan anak.

Penelitian ini menggunakan metode forward chaining untuk mesin inferensi di sistem pakar yang dibangun. Teknik inferensi ini dipilih karena Teknik ini telah sukses digunakan untuk sistem pakar [1].

\section{TINJAUAN PUSTAKA}

\section{A. Bakat Anak}

Bakat adalah adalah kemampuan dasar seseorang untuk belajar dalam tempo yang relatif pendek dibandingkan orang lain, namun hasilnya justru lebih baik. Bakat merupakan potensi yang dimiliki oleh seseorang sebagai bawaan sejak lahir. Bakat adalah suatu kondisi pada seseorang yang memungkinkannya dengan suatu latihan khusus mencapai suatu kecakapan, pengetahuan, 
keterampilan khusus [2]. Bakat juga mengandung makna kemampuan bawaan yang merupakan potensi yang masih perlu pengembangan dan latihhan lebih lanjut, karena sifatnya yang masih potensial tersebut maka masih memerlukan usaha pengembangan dan pelatihan secara serius dan sistematis agar dapat terwujud. Dengan bakat, memungkinan seseorang untuk mencapai prestasi dalam bidang tertentu jika dibarengi dengan latihan, pengetauan, pengalaman dan motivasi [3].

\section{B. Kepribadian}

Kecanduan atau addiction dalam Istilah kepribadian/personality berasal dari kata latin "persona" yang berarti topeng atau kedok, yaitu tutup muka yang sering dipakai oleh pemain-pemain panggung, yang maksudnya untuk menggambarkan perilaku, watak, atau pribadi seseorang. Kepribadian adalah keseluruhan cara seorang individu bereaksi dan berinteraksi dengan individu lain paling sering dideskripsikan dalam istilah sifat yang bisa diukur yang ditunjukkan oleh seseorang [4]. Kepribadian merupakan sesuatu yang menggambarkan ciri khas (keunikan) seseorang yang membedakan orang tersebut dengan orang lain. Dengan mengetahui kepribadian seseorang maka akan dapat meramalkan perilaku yang akan ditampilkan orang tersebut dalam menghadapi suatu situasi tertentu [5].

\section{Sistem Pakar}

Sistem pakar adalah suatu aplikasi dari kecerdasan tiruan yang dapat menyelesaikan masalah dalam bidang tertentu. Sistem pakar (Expert system) merupakan sistem yang berusaha mengadopsi pengetahuanmanusia ke komputer, agar komputer dapat menyelesaikan masalah seperti yang biasa dilakukan oleh para ahli [6]. Sistem pakar yang baik dirancang agar dapat menyelesaikan suatu permasalahan tertentu dengan meniru kerja dari para ahli. Sistem pakar adalah sebuah perangkat lunak komputer yang memiliki basis pengetahuan untuk domain tertentu dan menggunakan penalaran inferensi menyerupai seorang pakar dalam memecahkan suatu masalah yang di hadapi. Kekuatannya terletak pada kemampuan dalam memecahkan sebuah persoalan - persoalan taktis dan praktis pada saat sang pakar berhalangan ataupun tidak bisa menemui sang pakar secara langsung [7].

\section{Forward Chaining}

Forward chaining bekerja dengan data yang tersedia menggunakan aturan inferensi untuk mendapatkan data yang lain sampai kesimpulan didapatkan. Mesin inferensi menggunakan forward chaining mencari aturan inferensi sampai menemukan satu dari antecedent (klausa IF - THEN) yang benar [8].

Forward chaining (pelacakan ke depan) suatu rantai yang dicari atau dilintasi dari suatu permasalahan untuk memperoleh solusinya. Forward Chainingmerupakan pendekatan untuk mengontrol inferensi dalam sistem pakar berbasis aturan [9]. Forward Chaining memulai dari sekumpulan data menuju kesimpulan. Forward Chhaining digunakan dengan cara penalaran dimulai dari fakta terlebih dahulu (lihat Gambar 1) untuk menguji kebenaran hipotesis atau mencocokkan fakta atau pernyataan dimulai dari bagian sebelah kiri dulu [10].

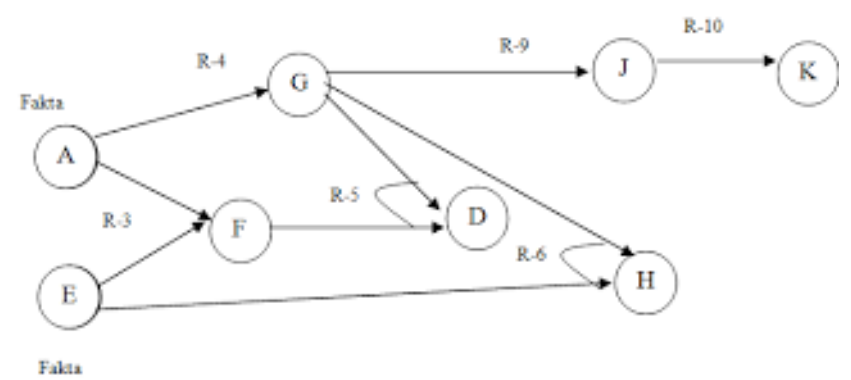

Gambar 1. Forward Chaining

\section{E. Metode SDLC Waterfall}

Metode System development life cycle (SDLC) Merupakan salah satu metode yang mempunyai ciri khas bahwa pengerjaan setiap fase harus dikerjakan terlebih dahulu sebelum melanjutkan ke fase berikutnya. Dengan demikian hasilnya akan fokus terhadap masing-masing fase sehingga pengerjaan dilakukan secara maksimal karena tidak adanya pengerjaan secara paralel.

Adapun kelebihan menggunakan metode waterfall diantaranya: 1. Urutan proses pengerjaan menggunakan metode ini menjadi lebih teratur dari satu tahap ke tahap yang selanjutnya. 2. Dari sisi user juga lebih menguntungkan karena dapat merencanakan dan menyiapkan seluruh kebutuhan data dan proses yang akan diperlukan 3. Jadwal menjadi lebih menentu karena jadwal setiap proses dapat ditentukan secara pasti. Sehingga dapat dilihat jelas target penyelesaian pengembangan program. Dengan adanya urutan yang pasti, dapat dilihat pula progress untuk setiap tahap secara pasti [11].

\section{METODOLOGI}

Penelitian ini menggunakan metode SDLC Waterfall, dimana dimulai dari requirements, design, implementasi, dan testing, seperti gambar 1. Sistem penelitian ini menggunakan model SDLC (System Development Life Cycle) merupakan pola yang digunakan untuk mengembangkan sebuah sistem perangkat lunak [12].

\section{Q REQUIREMENTS}

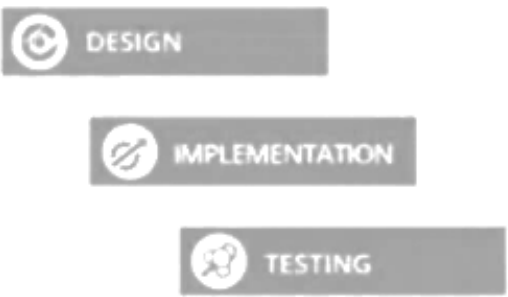

Gambar 2. Metode SDLC Waterfall 
Dalam penelitian ini menggunakan Forward-chaining. menyatakan kepercayaan dalam sebuah kejadian (fakta atau hipotesis) berdasarkan bukti atau penilaian pakar dengan melakukan pengujian terhadap sistem

\section{HASIL DAN PEMBAHASAN}

Jenis kepribadian yang digunakan adalah HipocratesGalenus yang menunjukkan adanya 4 (empat) kepribadian. Pada bagian ini akan dibahas mengenai basis pengetahuan tentang sifat, kepribadian dan bakat sesuai dengan pakarnya, terdapat pada table 1 .

Tabel 1. Jenis Kepribadian

\begin{tabular}{|c|c|}
\hline $\begin{array}{c}\text { Kode } \\
\text { Kepribadian }\end{array}$ & Nama Kepribadian \\
\hline K1 & Sanguine \\
\hline K2 & Plagmatis \\
\hline K3 & Melankolis \\
\hline K4 & Koleris \\
\hline
\end{tabular}

Jenis sifat disini digunakan untuk menentukan bakat. Berikut ini merupakan jenis sifat seperti tabel 2, jenis sifat digunakan untuk mengukur kedalaman anak.

Tabel 2. Jenis Sifat

\begin{tabular}{|c|c|}
\hline Kode & Keterangan sifat \\
\hline SF01 & Menyenangkan \\
\hline SF02 & Enerik \\
\hline SF03 & Bersemangat \\
\hline SF04 & Banyak bicara \\
\hline SF05 & Ramah \\
\hline SF06 & Jujur \\
\hline SF07 & Simpati \\
\hline SF08 & Antusias \\
\hline SF09 & Menarik \\
\hline SF10 & Periang \\
\hline SF11 & Caper \\
\hline SF12 & Baik Hati \\
\hline SF13 & Dinamis dan bijak \\
\hline SF14 & Bijaksana \\
\hline SF15 & Peduli \\
\hline SF16 & Mudah bergaul \\
\hline SF17 & Tenang \\
\hline SF18 & Rendah Hati \\
\hline SF19 & Percaya diri \\
\hline SF20 & Setia \\
\hline SF21 & Kreatif \\
\hline SF22 & Humoris \\
\hline SF23 & Idealis \\
\hline SF24 & Pengkritik \\
\hline SF25 & \\
\hline & \\
\hline
\end{tabular}

\begin{tabular}{|c|c|}
\hline SF26 & Disiplin \\
\hline SF26 & Mandiri \\
\hline SF27 & Keras kepala \\
\hline SF28 & EgoisTegas \\
\hline
\end{tabular}

Pada tabel 3 menjelaskan tentang hubungan kepribadian dengan jenis sifat yang digunakan untuk proses perhitungan penentuan keputusan dengan menentukan nilai forward chaining.

Tabel 3. Keputusan Bakat

\begin{tabular}{|c|c|c|c|c|}
\hline \multirow{2}{*}{ KodeSifat } & \multicolumn{4}{|c|}{ BAKAT } \\
\hline & BK1 & BK2 & BK3 & BK4 \\
\hline SF01 & V & & & \\
\hline SF02 & V & & & \\
\hline SF03 & V & & & \\
\hline SF04 & V & & & \\
\hline SF05 & V & & & \\
\hline SF06 & V & & & \\
\hline SF07 & V & & & \\
\hline SF08 & V & & & \\
\hline SF09 & V & & & \\
\hline SF10 & V & & & \\
\hline SF11 & V & & & \\
\hline SF12 & V & & & \\
\hline SF13 & & V & & \\
\hline SF14 & & V & & \\
\hline SF15 & & V & & \\
\hline SF16 & & V & & \\
\hline SF17 & & V & & \\
\hline SF18 & & V & & \\
\hline SF19 & & V & & \\
\hline SF20 & & V & & \\
\hline SF21 & & V & & \\
\hline SF22 & & V & & \\
\hline SF23 & & V & & \\
\hline SF24 & & V & & \\
\hline SF25 & & V & & \\
\hline SF26 & & & V & \\
\hline SF27 & & & V & \\
\hline SF28 & & & V & \\
\hline Kepribadian & KP01 & KP02 & KP03 & KP04 \\
\hline & & & & \\
\hline
\end{tabular}


Kemudian dilakukan proses analisis awal pada sistem pakar analisa bakat antara bakat, ciri bakat, dan solusi. Hasil yang didapatkan terlihat pada tabel 4.

Tabel 4. Bakat Anak Intelektual Umum

\begin{tabular}{|c|c|}
\hline Kode & Nama Indikator \\
\hline $\mathrm{C} 001$ & Dapat menirukan kalimat \\
\hline $\mathrm{C} 002$ & Dalam meniru Kembali urutan kata \\
\hline $\mathrm{C003}$ & Mengulangi lagu yang didengar \\
\hline $\mathrm{C} 004$ & Menyanyikan lagu lebih dari 20 \\
\hline $\mathrm{C005}$ & $\begin{array}{l}\text { Dapat mengelompokkan benda dengan berbagai } \\
\text { cara menurut fungsinya }\end{array}$ \\
\hline C006 & Meniru berbagai berbagai lambang huruf \\
\hline $\mathrm{C} 007$ & $\begin{array}{l}\text { Bercerita tentang gambar yang disediakan atau } \\
\text { dibuat sendiri }\end{array}$ \\
\hline $\mathrm{C} 008$ & Bercerita menggunakan kata ganti \\
\hline C009 & Menceritakan pengalaman \\
\hline $\mathrm{C} 010$ & $\begin{array}{l}\text { Memberikan keterangan/ informasi tentang suatu } \\
\text { hal }\end{array}$ \\
\hline $\mathrm{C} 011$ & Mengelompokkan benda \\
\hline $\mathrm{C} 012$ & $\begin{array}{l}\text { Dapat menggunakan dan dapat menjawab } \\
\text { pertanyaan }\end{array}$ \\
\hline
\end{tabular}

Pada tahap berikutnya menggambarkan flowmap dimana untuk merancang langkah-langkah dan urutan prosedur dari suatu program, seperti gambar 2 .

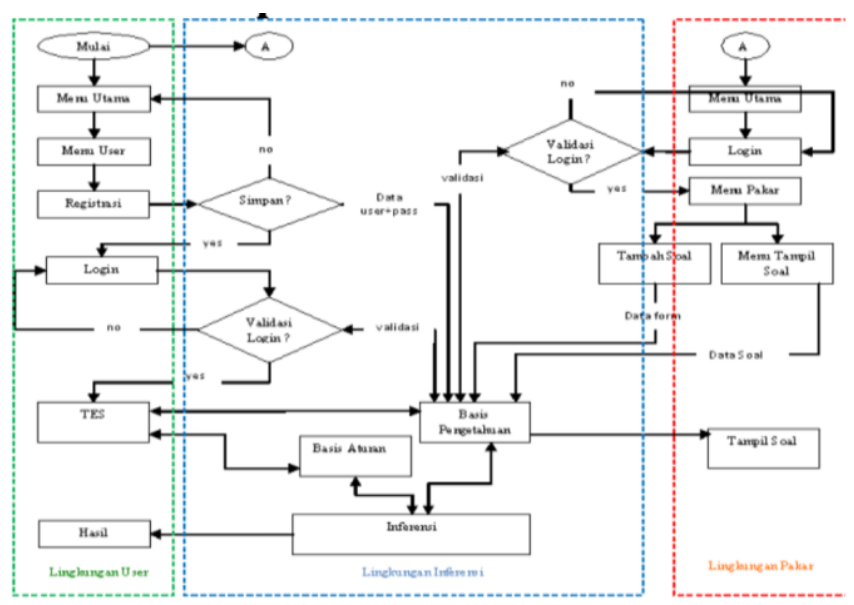

Gambar 2. Flowmap Sistem pakar dan bakat

Pada tahap ini Menyusun struktur menu sistem pakar untuk mengetahui bahat anak, pada gambar 3 .

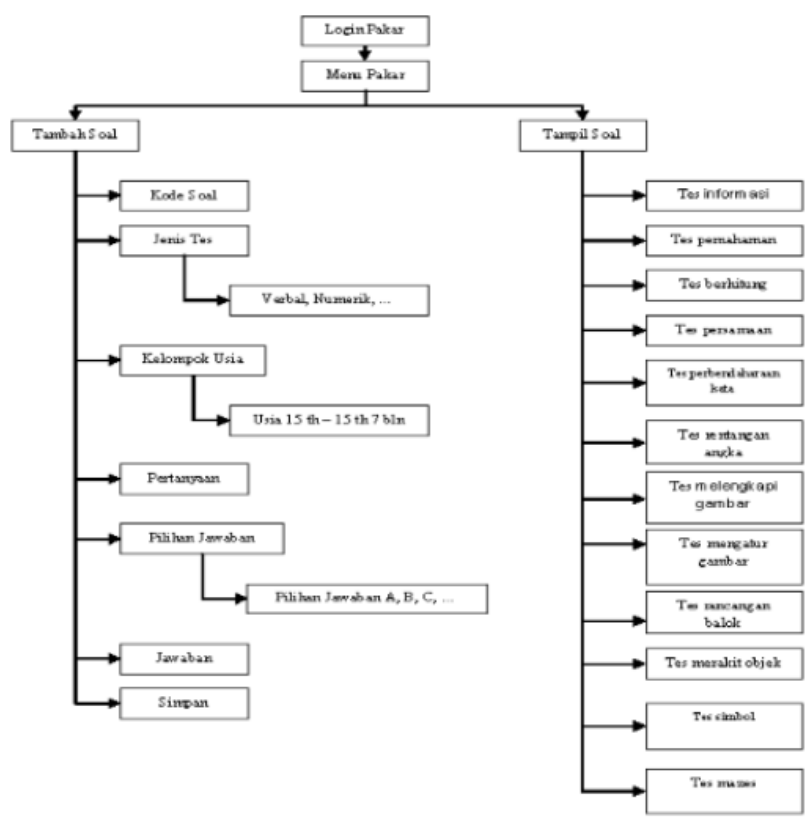

Gambar 3. Struktur menu sistem pakar untuk mengetahui bakat anak melalui tes

Pada Tahap ini menggambarkan aliran informasi pada sistem yang akan dikembangkan menggunakan activity diagram. Activity diagram menggambarkan berbagai jalur aktivitas dalam sistem yang sedang dirancang, bagaimana masing-masing aliran dimulai, keputusan yang mungkin terjadi, dan bagaimana aktivitas tersebut berakhir [13]. Pada activity diagram ini proses dari alur sistem pakar, seperti gambar 4.

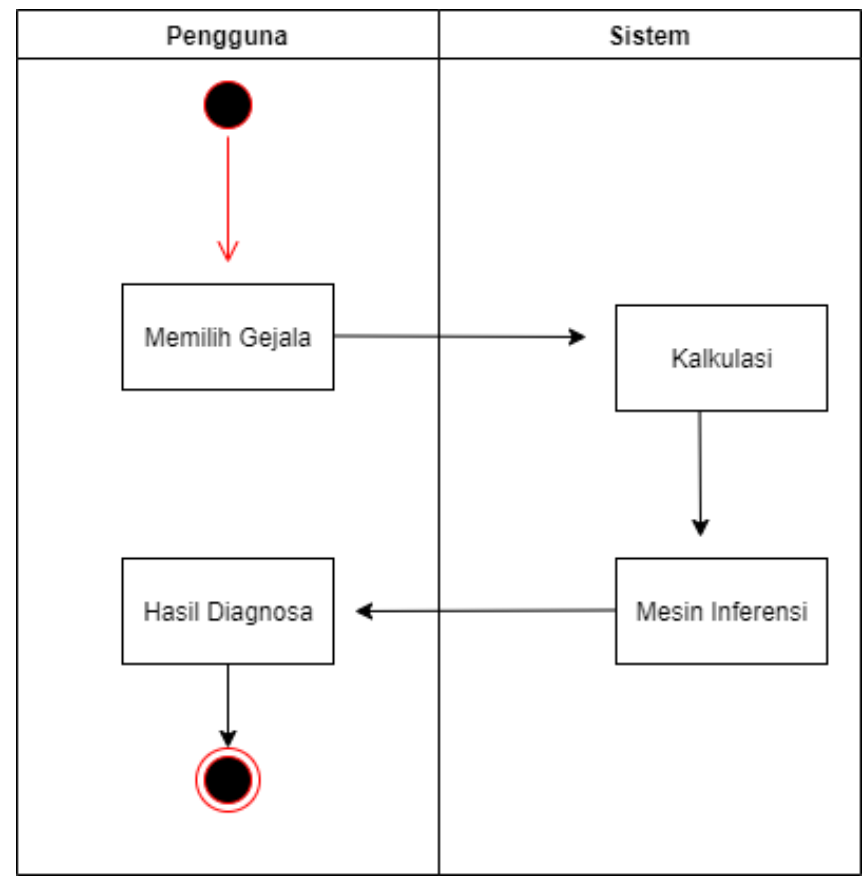

Gambar 4. Activity Diagram 
Pada tahap selanjutnya ini melakukan perancangan desain antarmuka sistem. Pada penelitian ini proses desain sistem hanya untuk pengguna.

Rancangan form login digunakan untuk user dalam mengakses ke menu utama. Sebelum masuk ke menu utama, user akan diminta untuk memasukkan username dan password seperti gambar 5 .

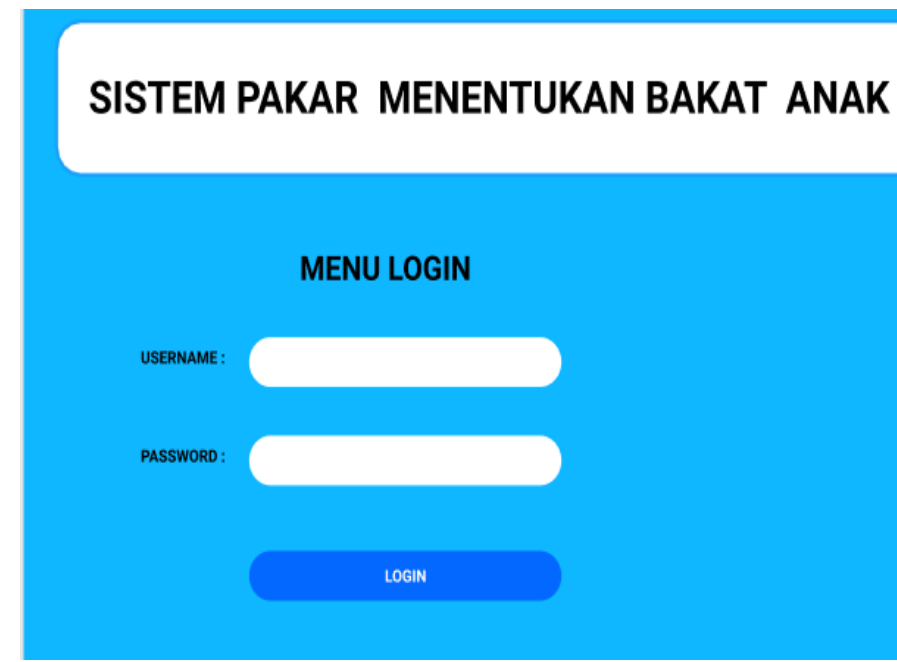

Gambar 5. Modul Form Login

Form menu utama akan muncul apabila username dan password yang dimasukkan user benar. Pada menu utama akan diberlakukan beberapa perbedaan hak akses sehingga menu akan tampil sesuai dengan jabatan yang diberikan, seperti gambar 6.

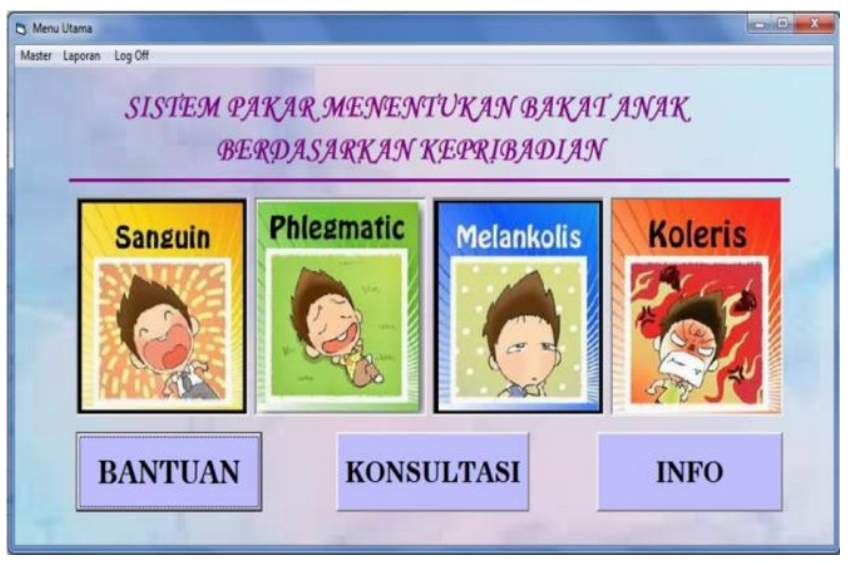

Gambar 6. Modul Form Menu Utama

Form konsultasi berisi pertanyaan-pertanyaan mengenai sifat dan kepribadian anak, kemudian user menjawab pertanyaan, dari jawaban user sistem memproses hasil jawaban kemudian menampilkan hasil Analisa, seperti gambar 7.

\section{SISTEM PAKAR MENENTUKAN BAKAT ANAK}

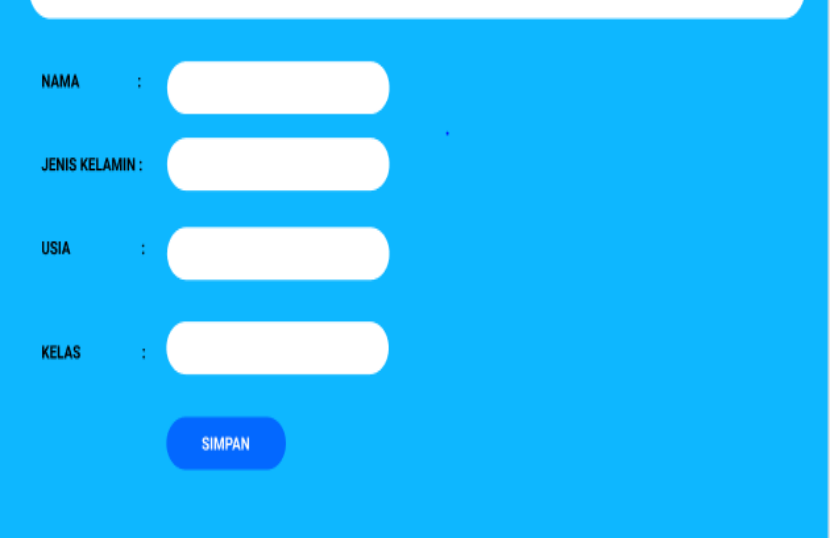

Gambar 7. Form Input Data Konsultasi

Tampilan print out hasil konsultasi menampilkan data user yang melakukan konsultasi, kepribadian, bakat serta ciri-ciri dengan menyertakan nilai/hasil persentase, pada gambar 8 .

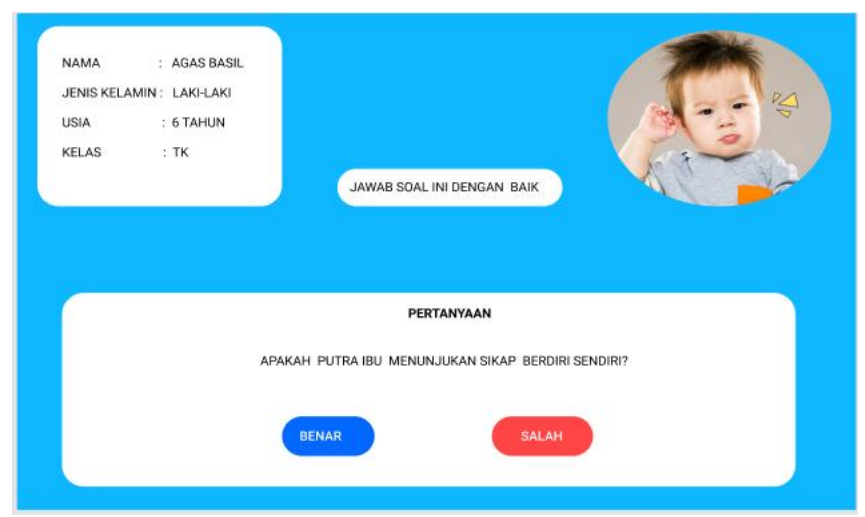

Gambar 8. Tampilan Print Out Hasil Konsultasi

\section{Kesimpulan}

Berdasarkan penelitian yang telah dilakukan, maka dapat diambil kesimpulan sebagai berikut:

1. Metode Forward Chaining juga dapat digunakan di suatu sistem pakar untuk mengidentifikasikan dan menentukan bakat anak pada kepribadiannya yang berdasarkan fakta dan masukkan yang di input dari pengguna.

2. Dengan adanya Sistem Pakar untuk menentukan bakat anak berdasarkan kepribadian dapat membantu pengguna (para orang tua) untuk dapat mengetahui tipe kepribadian anak sehingga orang tua dapat memberikan pola belajar yang sesuai dengan bakat kepribadian anak.

3. Aplikasi ini dapat membantu pengguna untuk dapat melakukan konsultasi online serta pengguna dapat mengenali bakat anak dari hasil dignosa tes kepribadian. 
4. Untuk pakar atau psikolog dengan adanya Sistem Pakar ini dapat membantu dalam memberikan informasi mengenai tipe kepribadian dan bakat kepada pengguna.

Adapun saran yang dapat dijadikan sebagai masukan antara lain:

1. Program sistem pakar untuk menentukan bakat anak berdasarkan kepribadian ini diharapkan dapat dikembangkan dengan menggunakan metode lainnya.

2. Pengembangan sistem pakar penentuan bakat anak berdasarkan kepribadian ini dapat di kembangkan dengan menggunakan aplikasi web maupun android untuk lebih mempermudah dalam penggunaannya.

3. Sistem pakar merupakan program yang sangat berguna bagi masyarakat luas, alangkah baiknya apabila sistem pakar ini dikembangkan dan diimplementasikan pada kasus-kasus lainnya.

\section{REFERENSI}

[1] Mohamad, S. N. dan Hashim, A, B, Frorward-Chaining Approach to Expert System for Machine Maintenance. Proceeding of Mechanical Engineering Researh Day, 79-80, 2015.

[2] D. P. Indah, Anton, and U. Radiyah, "Sistem pakar deteksi karakteristik dan kepribadian diri menggunakan metode forward chaining," JIMP - J. Inform. Merdeka Pasuruan, vol. 3, no. 1, pp. 34-43, 2018.
[3] Mohammad Ali dan Mohammad Asrori, Psikologi Remaja: Perkembangan Peserta Didik, (Jakarta: PT bumi aksara, 2014), hlm.78.

[4] L. G. Tri dkk, "Analisa Bakat Anak Melalui Penerapan Sistem Pakar Dengan Metode Forward Chaining," Pros. Semin. Nas. Multi Disiplin Ilmu, no. 207, pp. 103-111, 2016.

[5] Herlan Suherlan, Yono Budhiono, Psikologi Pelayanan, Media Perubahan, Bandung, 2013, hlm. 10.

[6] S.A. Lestari and R. I. Handayani, "Sistem Pakar Untuk Menentukan Bakat Anak Berdasarkan Kepribadian Menggunakan Model Forward Chaining," Bina Insa. Ict J., vol. 4, no. 1, pp. 47-56, 2017.

[7] Kusumadewi, S. Artificial Intelegence (Teknik dan Aplikasinya) Graha Ilmu, Yogyakarta. 2010.

[8] Arhami,M. Konsep Dasar Sistem Pakar, andi, Yogyakarta, 2008.

[9] Jurnal Rekayasa dan Manajemen Sistem Informasi, Vol. 1, No. 1, Februari 2015, pp.62-66 Laksana, Tri Ginanjar, dkk. 2016.

[10] Ani, A. Pemrograman sistem pakar. Yogyakarta: Mediakom. 2017.

[11] M. S. Rosa A.S, Rekayasa Perangkat Lunak. Bandung: Informatika Bandung, 2013.

[12] Pratiwi, H., Buku Ajar: Sistem Pakar, Kuningan: Goresan Pena, 2019.

[13] R. Maulany, B. Hasan, A. G. Abdullah, and D. Rohendi, "Design of learning applications using the Rapid Application Development method," IOP Conf. Ser. Mater. Sci. Eng., vol. 1098, no. 2, p. 022090, Mar. 2021 